\section{Does Colour-Coded Labelling Reduce the Risk of Medication Errors?}

\section{THE "PRO" SIDE}

The practice of colour-coding is controversial among patient safety groups because of insufficient evidence demonstrating that it is effective in reducing medication errors, ${ }^{1,2}$ the numerous problems that have been reported with the use of colour-code systems, ${ }^{3,4}$ and the availability of technology (bar-coding) that minimizes the human element in the final check during drug administration. ${ }^{5}$ Although the use of colour is often endorsed, ${ }^{6-8}$ inconsistent application of colour schemes can cause confusion and has contributed to medication misadventures. Despite these limitations, colour is used in various areas of medicine, and the following descriptions highlight some of the most common colour techniques.

Colour branding is commonly used to distinguish one product from others within the same class. Colour may also be used to identify a particular manufacturer, rather than emphasizing a particular drug or dosage, but this practice can contribute to picking errors.

Colour-coding is the systematic, standardized application of a colour system to classify and identify products, generally within the same pharmacologic class. ${ }^{2}$ Such systems allow people to match particular colours to specific functions. The majority of research in this area has focused on the use of colour-coding to reflect different levels of implied hazard. ${ }^{1}$ For example, red is perceived to represent a high hazard level. ${ }^{9}$ The Institute for Safe Medication Practices Canada has recommended the use of red packaging and labelling for neuromuscular blocking agents. ${ }^{10}$ Another example that will be familiar to many readers is the requirement to use black-cap packaging for potassium chloride concentrate. All manufacturers must now follow this directive because of the high potential risk that concentrated potassium chloride poses to the patient. ${ }^{11,12}$

Colour-coding systems are common in other areas of health care. For example, wristbands in standard colours have been used to identify patients with specific conditions (e.g., allergies). These wristbands help to prevent confusion that could lead to medication errors, misidentification, and death. ${ }^{13}$ Anesthesiologists in the United States, Australia, New Zealand, Canada, and Great Britain have adopted a colour-coding system for user-applied syringe labels for anesthetic drugs. Although the intention is to reduce the risk of error due to accidental syringe swapping, ${ }^{14}$ evidence for the effectiveness of this strategy is limited and mixed. ${ }^{15,16}$ The American Academy of Ophthalmology has recommended a uniform colour-coding system for the caps and labels of all topical ocular medications. ${ }^{17}$ The
Academy collaborated with the US Food and Drug Administration and industry to establish this colour system in response to reports of serious adverse events resulting from patients having difficulty distinguishing between different products. ${ }^{17}$

Colour matching uses colour to safely match one item to another. For example, a medical device may have a blue plug that inserts into a blue receptacle, a yellow plug that inserts into a yellow receptacle, and so forth. This technique has been used to match the length of a child (for an accurate estimation of weight) to a colour zone corresponding to appropriate drug doses, appropriate sizes of commonly used equipment (such as endotracheal and nasogastric tubes), and appropriate IV fluid volumes. Use of such a tool was associated with a significant reduction in deviation from recommended doses in simulated pediatric emergencies. ${ }^{18}$

Colour differentiation involves the use of colour to enhance features on labels and packaging, to help users discriminate one drug or product strength from another. Use of this colour technique enhances the noticeability of a label by increasing the speed and accuracy of label identification and the perceived readability of labels. ${ }^{1}$ In addition, label colour has been demonstrated to influence compliance levels, with higher levels of compliance being associated with red labels than with either black or green ones. ${ }^{1}$

By current convention, purple is used to denote oral syringes and yellow to denote epidural syringes. ${ }^{6}$ Yellow-striped tubing differentiates epidural tubing from regular IV tubing and is recommended to reduce the likelihood of mix-ups. ${ }^{19}$ In fact, yellow-striped tubing should never be used for anything other than epidural infusion. ${ }^{20}$ Anecdotal examples describe the successful use of colour differentiation to reduce other types of medication errors. ${ }^{8}$

In summary, the available literature favours the judicious use of 2 colour techniques: colour differentiation and colour matching. However, the effectiveness of any colour used on drug labels and packaging should be validated before it is adopted for that purpose. ${ }^{21}$ Colour-coding has not been tested as a way to prevent medication errors, and evidence exists that it may actually contribute to some errors. ${ }^{3}$ Colour-coding should therefore be used with extreme caution and only after international standardization.

\section{References}

1. Hellier E, Edworthy J, Derbyshire N, Costello A. Considering the impact of medicine label design characteristics on patient safety. Ergonomics 2006;49(5-6):617-630.

2. Meeting summary: Use of colour on pharmaceutical labeling and packaging Part 15 hearing. Bethesda (MD): Food and Drug Administration (US), Center for Drug Evaluation and Research; 2005 Mar 7 [cited 2008 Dec 18]. Available from: http://www.fda.gov/cder/meeting/part15_3_2005/ transcript.pdf 
3. A spectrum of problems with using colour. ISMP Med Saf Alert 2003 Nov 13 [cited 2008 Dec 18]. Available from: http:/www.ismp.org/newsletters/ acutecare/articles/20031113.asp

4. Wildsmith JAW. Doctors must read drug labels, not whinge about them. BMJ 2002;324(7330):170.

5. McKoy LK. Look-alike, sound-alike drugs review: include look-alike packaging as an additional safety check. Jt Comm J Qual Patient Saf 2005;31(1):47-53.

6. Design for patient safety: a guide to labeling and packaging of injectable medicines. National Patient Safety Agency (UK), Patient Safety Division; 2008 May [cited 2008 Dec 18]. Available from: http:// www.lyftingsmo.no/labelling/regulations\%20and\%20guidelines/ 0592_Injectables_book_V9_Web[1].pdf

7. Venkatraman R, Durai R. Errors in medicine administration: how can they be minimised? J Perioper Pract 2008;18(6):249-253.

8. Cohen MR. The role of drug packaging and labeling in medication errors. In: Cohen MR, editor. Medication errors. Washington (DC) American Pharmaceutical Association; 1999. pp 13.1-13.22.

9. Report 5 of the Council on Scientific Affairs. The role of colour coding in medication error reduction. Chicago (IL): American Medical Association; 2004 Jun.

10. Enhanced labeling of neuromuscular blocking agents makes a difference. ISMP Can Saf Bull 2007;7(5):3.

11. Potassium chloride for injection concentrate [monograph]. In: USP 23-NF 18 (United States Pharmacopeia and National Formulary). Rockville (MD): United States Pharmacopeial Convention, Inc; 1995. p 1254.

12. General requirements for tests and assays: ${ }^{1}$ Injections. In: USP 23-NF 18 (United States Pharmacopeia and National Formulary). Rockville (MD): United States Pharmacopeial Convention, Inc; 1995. p 1651.

13. LaserBand colour-code wristbands implemented by several states. Pharmacy Choice Inc; 2008 Oct 20 [cited 2008 Nov 25]. Available from: http://www.pharmacychoice.com/news/article.cfm?Article_ID $=143414$

14. Committee D10.32 on Consumer, Pharmaceutical and Medical Packaging. ASTM D4774-06 standard specification for user applied drug labels in anesthesiology. West Conshohocken (PA): ASTM International; [cited 2008 Dec 18]. Available from: http://www.astm.org/Standards/D4774.htm (payment required to download document).

15. Hirabayashi Y, Kawakami T, Suzuki H, Igarashi T, Saitoh K, Seo N. [The effect of coloured syringes and a coloured sheet on the incidence of syringe swaps during anesthetic management]. Masui 2005;54(9):1060-1062. Japanese.

16. Fasting S, Gisvold SE. Adverse drug errors in anesthesia, and the impact of coloured syringe labels. Can J Anaesth 2000;47(11):1060-1067.

17. Colour codes for topical ocular medications [policy statement]. San Francisco (CA): American Academy of Ophthalmology; 2006 Oct [cited 2008 Dec 18]. Available from: http://www.aao.org/about/policy/upload/ Color_Codes_for_Topical_Ocular_Medications.pdf

18. Shah AN, Frush K, Luo X, Wears RL. Effect of an intervention standardization system on pediatric dosing and equipment size determination: a crossover trial involving simulated resuscitation events. Arch Pediatr Adolesc Med 2003;157(9):229-236

19. Smetzer JL, Cohen MR. Epidural-intravenous route mix-ups: reducing the risk for deadly errors. Hosp Pharm 2008;43(10):788-792.

20. Don't use epidural tubing for an IV solution. ISMP Med Saf Alert 2008 Jan 17 [cited 2008 Dec 18]. Available from: http://www.ismp.org/ newsletters/acutecare/articles/20080117-1.asp

21. APA statement on the use of colour coding. Washington (DC): American Psychological Association; [cited 2008 Dec 18]. Available from: http://www.apa.org/ppo/issues/apacolorcoding.pdf

Paul Filiatrault, BSc(Pharm)

Manager, Medication Safety and Standards

Regional Pharmacy

Interior Health

Kelowna, British Columbia

\section{Acknowledgements}

I thank Warren Rosart for advice on the draft manuscript and Julie Polisena and Mary-Doug Wright (at the Health Technology Inquiry Service of the Canadian Agency for Drugs and Technology in Health) for their assistance in the literature search.

\section{THE "CON" SIDE}

Colour-coding is a system of using colours to categorize elements within a set of some kind, for example, to identify a particular drug or a therapeutic class of drugs. The concept of colour-coding and its application to pharmaceutical products as a way to enhance medication safety is a complex topic. Although ISMP Canada does not have an official position on colourcoding of pharmaceuticals, our experience in this field leads me to argue against colour-coding for pharmaceutical product labelling.

I would like to begin with 2 distinctions that are relevant to this discussion. First is the distinction between colour-coding and the use of colour to enhance label design. In a colour-coding system, the colour itself has a specific meaning. In contrast, when colour is used in label design, it gives prominence to critical information by highlighting that information (thus differentiating certain details), but there is no meaning inherent in the colour itself. The second distinction is between colour-coding of pharmaceutical products and colour-coding of devices. Use of yellow infusion tubing for epidural administration of medications has been advocated, and we could imagine the use of matching yellow minibags and syringes for the medications themselves. In this situation, the colour yellow would have a particular meaning and ideally would be a redundant cue, complementing intelligent design features, such as unique connectors to ensure incompatibility and separation of epidural administration systems from intravenous administration systems.

The greatest limitation to colour-coding of pharmaceuticals is the limited number of absolute identifiable colours: fewer than 10 . Yet there are many classes or categories of drugs, many lookalike pairs of medication names, and thousands of marketed pharmaceutical products. Also, given the known limitations of human memory, it may be unreasonable to expect health care providers (including physicians, nurses, pharmacists, and technicians) to remember multiple or complex colour-coding systems.

Some groups have attempted to apply colour-coding to pharmaceuticals within their respective specialties. A 2004 review by the Council on Scientific Affairs of the American Medical Association identified 2 examples of colour-coding of pharmaceuticals: one in the field of ophthalmology and the other in anesthesiology. ${ }^{1}$ So far, no clear evidence has emerged to indicate that colour-coding of pharmaceuticals in these fields is beneficial. Fasting and Gisvold ${ }^{2}$ reported that drug errors in anesthesia are uncommon, representing only a small proportion of anesthesia problems but having the potential for serious morbidity. They concluded that inadvertent syringe swaps most often involved syringes of equal size, and this type of switch was not prevented by colour-coding syringe labels. 
The application of colour-coding might have limited success if the specialty setting can be controlled and standardized, but if the setting grows and a greater number of different colours is required, or if the number of people handling medications increases, the potential advantages of colour-coding might be outweighed by potential confusion. Furthermore, the risk of substitution errors could also increase if products typically used outside the particular specialty happen to have similar packaging and colour. The Institute for Safe Medication Practices (ISMP) in the United States has promoted the use of colour-coding for user-applied labels in anesthesia (i.e., when anesthesia drugs are prepared in a syringe and labelled in the operating room). This organization notes that the standardized colours developed by the American Society for Testing and Materials are intended to differentiate drug classes and that, in most cases, anesthesia providers require only one product from each class. ${ }^{3}$ ISMP (US) emphasizes that the colour-coding system for anesthesia products was not designed for commercial product labels and warns against use of commercially available colour-coded, prefilled syringes outside the operating room. Mix-ups due to selection errors among products within a class of drugs (e.g., morphine, fentanyl, and hydromorphone) could cause serious harm.

Another area of interest is the potential use of colour for labelling of manufacturer-prepared solutions for IV administration. In this context, products containing medications must be well differentiated from infusion solutions that do not contain medications (e.g., $0.9 \%$ sodium chloride or $5 \%$ dextrose in water). For example, the use of red type for the name of a medication in a manufacturer-prepared infusion bag gives a redundant cue that the solution contains a medication. Some readers may feel that the preceding statement amounts to an argument in favour of a form of colour-coding for pharmaceutical product labelling. In my view, however, this position is consistent with a recommendation to use colour to give prominence to critical information.
In summary, the use of colour-coding for pharmaceutical product labelling is problematic because of the limited number of truly different colours and the large number of pharmaceutical products, classes, and categories. Nonetheless, the use of such colour-coding within specialties, such as anesthesiology and ophthalmology, warrants further study. In fact, this issue represents an opportunity for health care stakeholders, such as health care professionals, drug manufacturers, experts in the field, and regulators, to collaborate in gathering evidence (undertaking further research if required) and developing a position statement to guide practice. Such a position statement should elaborate on the use of colour to enhance label design and differentiation and the use of colour-coding to distinguish devices for different forms of drug administration; it should also recognize that optimal design does not rely on colour alone and should take into account the characteristics of the global pharmaceutical industry. The International Medication Safety Network or the World Health Organization would be ideally situated to lead such an effort.

\section{References}

1. Report 5 of the Council on Scientific Affairs (A-04) full text. The role of color coding in medication error reduction. Chicago (IL): American Medical Association; 2004 [updated 2006 Sep 30, cited 2008 Oct 31]. Available from: www.ama-assn.org/ama/pub/category/print/13662.html

2. Fasting $S$, Gisvold SE. Adverse drug errors in anesthesia, and the impact of coloured syringe labels. Can J Anesth 2000;47(11):1060-1067.

3. Colour-coded syringes for anesthesia drugs: use with care. ISMP Med Saf Alert 2008;13(25):1-2.

Sylvia Hyland, RPh, BScPhm, MHSc

Vice President and Chief Operating Officer

Institute for Safe Medication Practices Canada

Toronto, Ontario 